\title{
Herbal Medicines in the Management of Urolithiasis: Alternative or Complementary?
}

\author{
Authors \\ Affiliations \\ Veronika Butterweck ${ }^{1}$, Saeed R. Khan ${ }^{2}$ \\ 1 College of Pharmacy, Department of Pharmaceutics, University of Florida, Gainesville, Florida, USA \\ ${ }^{2}$ College of Medicine, Department of Pathology, Immunology \& Laboratory Medicine, University of Florida, Gainesville, \\ Florida, USA
}

Key words
kidney stones
urolithiasis
nephrolithiasis
calcium oxalate
oxalates
citrates
plant extracts
alternative medicine
complementary medicine

revised March 29, 2009

accepted April 7, 2009

Bibliography

DOI 10.1055/s-0029-1185719

Published online May 14, 2009

Planta Med 2009; 75 :

1095-1103 @ Georg Thieme

Verlag KG Stuttgart . New York . ISSN 0032-0943

\section{Correspondence}

\section{Dr. Veronika Butterweck}

Department of Pharmaceutics,

College of Pharmacy

University of Florida

P. O. Box 100494

Gainesville, FL 32610

USA

Phone: + 13522737859

Fax: + 13522737854

butterwk@cop.ufl.edu

\section{Abstract \\ $\nabla$}

Kidney stone formation or urolithiasis is a complex process that results from a succession of several physicochemical events including supersaturation, nucleation, growth, aggregation, and retention within the kidneys. Epidemiological data have shown that calcium oxalate is the predominant mineral in a majority of kidney stones. Among the treatments used are extracorporeal shock wave lithotripsy (ESWL) and drug treatment. Even improved and besides the high cost that imposes, compelling data now suggest that exposure to shock waves in therapeutic doses may cause acute renal injury, decrease in renal function and an increase in stone recurrence. In addition, persistent residual stone fragments and the possibility of infection after ESWL represent a serious problem in the treatment of stones. Furthermore, in spite of substantial progress in the

\section{Introduction}

\section{$\nabla$}

Urinary stones affect $10-12 \%$ of the population in industrialized countries [1,2]. There are only a few geographical areas in which stone disease is rare, e.g., in Greenland and in the coastal areas of Japan [2]. The incidence of urinary stones has been increasing over the last years while the age of onset is decreasing [3]. With a prevalence of $>10 \%$ and an expected recurrence rate of $\sim 50 \%$, stone disease has an important effect on the healthcare system [4]. Once recurrent, the subsequent relapse risk is raised and the interval between recurrences is shortened [1]. Features associated with recurrence include a young age of onset, positive family history, infection stones and underlying medical conditions [1]. Epidemiological studies revealed that nephrolithiasis is more common in men (12\%) than in women (6\%) and is more prevalent between the ages of 20 to study of the biological and physical manifestations of kidney stones, there is no satisfactory drug to use in clinical therapy. Data from in vitro, in vivo and clinical trials reveal that phytotherapeutic agents could be useful as either an alternative or an adjunctive therapy in the management of urolithiasis. The present review therefore critically evaluates the potential usefulness of herbal medicines in the management of urolithiasis.

$\begin{array}{ll}\text { Abbreviations } \\ \nabla \\ \text { CaOx: } & \text { calcium oxalate } \\ \text { CaP: } & \text { calcium phosphate } \\ \text { EG: } & \text { ethylene glycol } \\ \text { ESWL: } & \text { extracorporeal shock wave lithotripsy } \\ \text { Ox: } & \text { oxalate } \\ \text { URS: } & \text { ureteroscopy }\end{array}$

40 in both sexes [5]. The etiology of this disorder is multifactorial and is strongly related to dietary lifestyle habits or practices [6]. Increased rates of hypertension and obesity, which are linked to nephrolithiasis, also contribute to an increase in stone formation [7].

Management of stone disease depends on the size and location of the stones (see below). Stones larger than $5 \mathrm{~mm}$ or stones that fail to pass through should be treated by some interventional procedures such as extracorporeal shock wave lithotripsy (ESWL), ureteroscopy (URS), or percutaneous nephrolithotomy (PNL) [8]. Unfortunately, the propensity for stone recurrence is not altered by removal of stones with ESWL and stone recurrence is still about 50\% [9]. In addition, ESWL might show some significant side effects such as renal damage, ESWL induced hypertension or renal impairment [10]. 


\begin{tabular}{|c|c|c|}
\hline Condition & Definition & Causes \\
\hline \multirow[t]{3}{*}{ Hypercalciuria } & urinary calcium excretion $>200 \mathrm{mg} / \mathrm{d}$ & absorptive hypercalciuria: $\uparrow$ Gl calcium absorption \\
\hline & & renal hypercalciuria: impaired renal Ca absorption \\
\hline & & resorptive hypercalciuria: primary hyperparathyroidism \\
\hline \multirow[t]{3}{*}{ Hyperoxaluria } & urinary oxalate excretion $>40 \mathrm{mg} / \mathrm{d}$ & primary hyperoxaluria: genetic Ox overproduction \\
\hline & & dietary hyperoxaluria: excessive dietary intake \\
\hline & & enteric hyperoxaluria: $\uparrow \mathrm{Gl}$ oxalate absorption \\
\hline \multirow[t]{4}{*}{ Hypocitraturia } & urinary citrate excretion $<320 \mathrm{mg} / \mathrm{d}$ & $\begin{array}{l}\text { distal renal tubular acidosis: impaired renal tubular acid } \\
\text { excretion }\end{array}$ \\
\hline & & chronic diarrheal syndrome: $\mathrm{Gl}$ alkali loss \\
\hline & & thiazide-induced: hypokalemia \\
\hline & & $\begin{array}{l}\text { idiopathic hypocitraturia: high animal protein diet, } \\
\text { excessive physical exercise, high sodium intake }\end{array}$ \\
\hline Hyperuricosuria & urinary acid excretion > $>000 \mathrm{mg} / \mathrm{d}$ & $\begin{array}{l}\text { dietary purine excess, uric acid overproduction or over- } \\
\text { excretion }\end{array}$ \\
\hline Hypomagnesuria & urinary magnesium excretion $<50 \mathrm{mg} / \mathrm{d}$ & limited intake of magnesium-rich foods \\
\hline Gouty diathesis & urinary $\mathrm{pH}<5.5$ & etiology unknown \\
\hline
\end{tabular}

Table 1 Major causes of calcium stone formation $[5,14]$.

Abbreviations: $\mathrm{Gl}=$ gastrointestinal; $\mathrm{Ca}=$ calcium, $\mathrm{Ox}=$ oxalate; $\uparrow$ = increased

Although there are a few recent reports of beneficial effects of medical treatments in enhancing clearance of stones in the distal ureters [11], de facto there is still no satisfactory drug to use in clinical therapy, especially for the prevention or the recurrence of stones. In this regard, many plants have been traditionally used to treat kidney stones and have been shown to be effective.

The purpose of this paper is to critically review available literature on herbal medicines and their possible role in the management of urolithiasis. Using the key words "urolithiasis and plant extract", "nephrolithiasis and plant extract", "kidney stones and plant extract", a Medline research revealed 116 articles published between 1 January 1966 and 1 December 2008. Only those studies were included into the present analysis which were written in English or German and which represented original research articles. A total of 75 studies met the inclusion criteria and were further subclassified into in vitro $(\mathrm{n}=13)$, in vivo $(\mathrm{n}=41)$, and clinical studies $(n=21)$. The included studies were further evaluated with respect to the proximate phytochemical composition of the plant extract and the possible mechanism of action.

\section{Pathophyiology of Nephrolithiasis}

Kidney stones are classified according to their chemical composition. Crystallization and subsequent lithogenesis can happen with many solutes in the urine. For crystals to form, urine must be supersaturated with respect to the stone material, meaning that concentrations are higher than the thermodynamic solubility for that substance. Levels of urinary supersaturation correlate with the type of stone formed, and lowering supersaturation is effective for preventing stone recurrence $[5,12]$. Calcium oxalate $(\mathrm{CaOx})$ is the predominant component of most stones accounting for more than $80 \%$ of stones $[1,13]$. The remaining $20 \%$ are composed of struvite, cystine, uric acid, and other stones [14]. As mentioned above, the basis for calcium stone formation is supersaturation of the urine with stone-forming calcium salts. Metabolic abnormalities such as hypercalciuria, hypocitraturia, hyperoxaluria, hyperuricosuria, and gouty diathesis can change the composition or saturation of the urine so as to enhance stone formation $[5,15]$. In patients who have $\mathrm{CaOx}$ stones, for example, urine uric acid excretion may be elevated, often as a result of excessive protein intake. Hyperuricosuria decreases the solubility of
$\mathrm{CaOx}$ and promotes stone formation by heterologous nucleation on the surface of monosodium urate levels $[5,15]$. However, patients who have hyperuricosuric calcium stones differ from patients who have gout and uric acid stones in having a higher urine $\mathrm{pH}$ and a higher uric acid level as well $[5,15]$. Since it is beyond the scope of the present review to discuss all of these metabolic abnormalities in greater detail, a brief summary is provided in - Table 1. Besides Ca or Ox, human urine also contains other ions and macromolecules that can interact with both ions and modulate crystallization [16]. Any cellular dysfunction that can affect various urinary ions and other substances can also influence $\mathrm{CaOx}$ supersaturation and crystallization in the kidneys. Crystal formation, particularly of calcium phosphate (CaP) and $\mathrm{CaOx}$, within the urinary tract is widespread. Since humans excrete millions of urinary crystals daily without developing kidney stones, at least a transient development of supersaturation is likely [16]. However, supersaturation is only one step in the process of stone formation. For stone formation crystals need to be retained within the kidney and they should also be located at sites from where crystals can ulcerate to the renal papillary surface to form a stone nidus [17]. Renal injury promotes crystal retention and the development of a stone nidus on the renal papillary surface and further supports crystal nucleation at lower supersaturation [18]. Thus, one approach to prevent stone formation would be to stop crystal retention. Since supersaturation is essential for the production of stones another major therapeutic goal is the reduction of supersaturation [16]. Reactive oxygen species (ROS) seem also to be responsible for cellular injury, therefore a reduction of renal oxidative stress could also be an effective therapeutic approach [19].

In conclusion, the pathogenesis of kidney stone formation is not a simple process and varies largely based on the stone phenotype [15]. Although several theories exist to explain the pathogenesis of renal calculi, the exact cascade of events that lead to kidney stone formation is still unclear. 


\section{Current Treatment/Prevention Options}

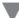

\section{Treatment}

The accepted management of stone disease ranges from observation (watchful waiting) to surgical removal of the stone. Various factors such as size of calculi, severity of symptoms, degree of obstruction, kidney function, location of the stone and the presence or absence of associated infection influence the choice of one type of intervention over the other [9].

Stones which are smaller than $5 \mathrm{~mm}$ have a high probability of spontaneous passage which can take up to 40 days [8]. During this watchful waiting period, patients can be treated with hydration and pain medication [4]. However, stones larger than $5 \mathrm{~mm}$ or stones that fail to pass are treated by interventional procedures [4]. Open surgical procedures for the treatment of ureteric stones have gradually disappeared in the last 30 years and have been replaced by minimal invasive techniques such as ESWL or ureteroscopy.

ESWL is a noninvasive procedure which uses shock waves to fragment calculi [20]. This technique is the most widely used method for managing renal and ureteral stones. However, treatment success rates depend on stone composition, size, properties and location of the stone as well as the instrumentation type and shock frequency [4]. It also needs to be considered that the same forces that are directed at the stones have deleterious effects on surrounding tissues [20]. Damage to almost every abdominal organ system has been reported $[21,22]$, but by far the most common injury is acute renal hemorrhage although its true incidence is unclear and poorly defined [20]. Most often renal hemorrhage can be managed conservatively; however, in rare instances the complications are fatal [20]. Reports of post-ESWL perirenal hematoma range from less than $1 \%$ to greater than $30 \%$ [23]. Furthermore, ESWL has been associated with long-term medical effects such as diabetes mellitus and hypertension [24].

In addition to ESWL, other procedures such as ureteroscopy (URS) have been developed for removal of ureteral stones. The new generations of uteroscopes are flexible, smaller in diameter, stiffer and more durable, and have an improved tip deflection [4]. The major drawback of URS is that it is more invasive than ESWL and the rate of ureteric perforation and stricture formation remains around 2 to $4 \%$. [25]. In contrast, the major advantage of URS is that it is cheaper and results in higher and faster stonefree rates $[4,9]$. It remains unclear which treatment modality is better than the other and the final decision should be based on the patient's preference, on the size and the location of the stone, expertise of the physician and the costs of the procedure [4].

\section{Prevention}

Despite the major technical achievements for stone removal in the last three decades the problem of recurrent stone formation remains. As mentioned earlier the recurrence rate of kidney stones is approximately $15 \%$ in the first year and as high as $50 \%$ within five years of the initial stone [2]. Effective kidney stone prevention is dependent on the stone type and the identification of risk factors for stone formation. An individualized treatment plan incorporating dietary changes, supplements, and medications can be developed to help prevent the formation of new stones. Regardless of the underlying etiology of the stone disease, patients should be instructed to increase their fluid intake in order to maintain a urine output of at least 2 L/d [14]. A high fluid intake reduces urinary saturation of stone-forming calcium salts and dilutes promoters of CaOx crystallization [14]. A high sodium intake increases stone risk by reducing renal tubular calcium reabsorption and increasing urinary calcium. Patients should be advised to limit their dietary sodium intake to $2000-3000 \mathrm{mg} / \mathrm{d}$ [14]. A restriction of animal proteins is also encouraged since animal proteins provide an acid load because of the high content of sulfur-containing amino acids. Thus, a high protein intake reduces urine $\mathrm{pH}$ and citrate and enhances urinary calcium excretion via bone resorption and reduces renal calcium reabsorption [26]. Stone formers should not be advised to restrict calcium unless it has been shown that they have an excessive intake of calcium [2]. A reduced intake of calcium leads to an increased intestinal absorption of oxalate, which itself may account for an increased risk of stone formation [14]. Vitamin C has been implicated in stone formation because of in vivo conversion of ascorbic acid to oxalate. Therefore, a limitation of vitamin C supplementation to $500 \mathrm{mg} / \mathrm{d}$ or less is recommended [14].

When dietary modification is ineffective, pharmacological treatment should be initiated. The most effective hypocalciuric agents are thiazide diuretics which hypocalciuric action enhance calcium reabsorption in the distal renal tubules [27]. However, longterm use in up to $50 \%$ of patients is limited because of side effects including fatigue, dizziness, impotence, musculoskeletal symptoms, or gastrointestinal complaints [14]. Another complication is thiazide-induced potassium depletion, which causes intracellular acidosis and can lead to hypokalemia and hypocitraturia [1]. Potassium citrate is effective in the treatment of patients who have calcium stones and normal urinary calcium. By providing an alkali load, potassium citrate increases urinary $\mathrm{pH}$ and citrate, therefore mediating the inhibitory effects of macromolecular modulators of calcium oxalate crystallization [28]. The main limitation for a more widespread use of alkali citrate preparations is the relatively low tolerability of available alkali citrate preparations. Adverse effects that reduce treatment compliance have been noted mainly in the gastrointestinal tract and include eructation, bloating, and diarrhea [28]. In conclusion, none of the listed treatment modalities is without any side effects. Thus, the focus should be on the development of novel strategies for the prevention and treatment of kidney stone disease. Herbal medicines could close a gap in this regard.

\section{Currently Used Herbal Medicines}

\section{$\nabla$}

\section{In vitro studies}

In vitro systems for experimental nephrolithiasis can be differentiated into systems investigating the physical chemistry of stone formation or systems that explore the pathophysiology of renal stone disease. For the first purpose, in vitro crystallization systems are widely used to study processes of crystal nucleation, growth and agglomeration [29]. For the latter one, cultured renal epithelial cell lines are widely accepted as a tool to explore the mechanism of urolithiasis [30].

From the 13 in vitro studies that met the inclusion criteria for the present review, 7 articles focused on calcium oxalate crystallization in the presence or absence of a particular plant extract, in 3 articles a cell culture system was used to investigate the effects of an extract on oxalate-induced cell injury and a further 3 articles used either a combination of both techniques or included an additional in vivo experiment.

Various herbs have been reported to inhibit $\mathrm{CaOx}$ crystallization. Atmani and Khan [31] have reported that an extract from the herb Herniaria hirsuta L., a plant that traditionally is used in Mo- 
rocco for the treatment of lithiasis, promoted the nucleation of calcium oxalate crystals, increasing their number but decreasing their size. In a follow-up study the authors could demonstrate that $H$. hirsuta could block crystal binding to cultured renal cells [32]. Similar effects on calcium oxalate crystallization in vitro have been shown for an aqueous extract from Phyllantus niruri L., a plant which is used in traditional Brazilian medicine for the treatment of stone disease [33]. The authors could show that the extract interfered with the $\mathrm{CaOx}$ crystallization process by reducing $\mathrm{CaOx}$ crystal growth and aggregation [33]. In an earlier study, Campos and Schor [34] investigated the in vitro effect of $P$. niruri on a model of CaOx crystal endocytosis by Madin-Darby canine kidney cells. The extract exhibited a potent and effective nonconcentration-dependent inhibitory effect on the CaOx crystal internalization. Garimella et al. [35] demonstrated that an extract prepared from the seeds of Dolichos biflorus L. [now Vigna unguiculata (L.) Walp. subsp. Unguiculata] which is used in traditional Indian Ayurvedic medicine could inhibit the precipitation of calcium and phosphate in vitro. Several traditional Chinese medicines (TCM) or plants that are used in Kampou medicine also have demonstrated their abilities to inhibit calcium oxalate crystallization [36,37]. Dietary factors appear to affect the ability of urine to inhibit $\mathrm{CaOx}$ crystallization. In this regard, lemon juice has been found to inhibit the rate of crystal nucleation and aggregation $[38,39]$. Overall, the in vitro crystallization experiments confirmed that prophylaxis of renal stones could be achieved by reducing supersaturation through promotion of small crystal nucleates.

As mentioned above, in vitro studies using renal epithelial cell lines are useful to perform mechanistic studies on urolithiasis. In this regard, oxalate, a major constituent of $\mathrm{CaOx}$ stones, has been shown to exert cytotoxic effects on renal tubular epithelial cells, attributable to increased oxidative stress within the cells [40]. Oxalate seems to induce cell death mediated by both apoptosis and cellular necrosis, since oxalate exposure leads to the formation of apoptotic bodies as well as induces changes in membrane integrity, the release of cellular enzymes, and membranelipid peroxidation [41]. It could be shown recently that an extract prepared from Quercus salicina Blume/Quercus stenophylla Makino could suppress cell injury induced by oxalate exposure by scavenging free radicals and suppressing the activation of NADPH oxidase [42]. Similar effects were reported for epigallocatechin gallate (EGCG) from green tea which also inhibited free radical production induced by oxalate [43].

In summary, the reported in vitro studies are promising since they have shown an inhibition of oxalate crystallization or antioxidative action. However, the overall limitation of all the listed studies is that the plant extracts have not been further phytochemically characterized. As a consequence, the validity of the studies is limited since without phytochemical characterization, quality control is difficult and reproducibility of results questionable. In addition, only two studies addressed the presence of oxalate in plant extracts $[31,43]$, a fact that needs to be considered for in vitro crystallization experiments in order to exclude false negative effects. Since many extracts contain oxalate (and/or citrate) per se, the quantitative amount of both molecules should be taken into account for future in vitro studies.

\section{In vivo studies}

As mentioned in the previous paragraph, in vitro models relate to only one event and one aspect of the process (e.g., crystallization studies determining nucleation and growth). In order to under- stand all aspects of the pathogenesis, including the anatomic and physiological role of kidneys, animal models are frequently used [44]. Most of the data available on renal physiology are based on experiments in rats, rabbits and dogs, however, rats are the animals most commonly used for the study of nephrolithiasis [44]. Since $80 \%$ of all kidney stones are composed of calcium oxalate [14], $\mathrm{CaOx}$ nephrolithiasis has been studied in greater detail. Stones formed in kidneys of humans and rats are identical at the ultrastructural level in both the nature and the composition of their matrix [44], thus, rat models of nephrolithiasis are helpful experimental tools for exploring the pathophysiology of this disease. CaOx kidney nephrolithiasis is produced in rats by the induction of acute or chronic hyperoxaluria using a variety of agents such as sodium oxalate, ammonium oxalate, hydroxyL-proline, ethylene glycol, and glycolic acid. Lithogenic agents are generally dispensed orally in food or water or by gavage but also have been injected intraperitoneally [44].

In $\odot$ Table 2, plants of different ethnobotanical regions are listed for which data from animal experiments exist and which met the inclusion criteria for the present review. A regional distribution of the emphasis in nephrolithiasis research is noticeable, the majority of animal studies have been performed using plants from Indian folk medicine (11), followed by plants traditionally used in Japan (3), Brasil (2), Mexico (2), Morocco (2) or China (2). From the listed herbs in Table [2] more than one animal study has been reported for Takusha (4 studies), Herniaria hirsuta L. (3 studies), and Phyllantus niruri L. (2 studies).

Takusha (Alisma orientale [Sam]. Juz), one of the components of the kampo medicine chorei-to is commonly used in Japan to cure and to prevent recurrent $\mathrm{CaOx}$ kidney stones. Studies in rats receiving ethylene glycol to induce $\mathrm{CaOx}$ stone formation have shown that Takusha prevented stone formation by inhibiting CaOx aggregation $[37,45]$. In cats fed with a diet containing Takusha, a reduction of urine $\mathrm{pH}$ was observed as well as reduced struvite crystal formation in cat urine $[46,47]$.

As mentioned in the previous paragraphs, Herniaria hirsuta and Phyllantus niruri have been shown to interfere with the $\mathrm{CaOx}$ crystallization process by reducing $\mathrm{CaOx}$ crystal growth and aggregation in in vitro studies [32,33]. Atmani et al. [48] could demonstrate that oral administration of a Herniaria hirsuta extract to experimentally induced $\mathrm{CaOx}$ nephrolithiasis in rats reduced the deposition of crystals in the kidneys. The observed activity was unrelated to diuresis or urinary biochemical changes [49]. Contrarily, Grases et al. [50] reported a diuretic effect after rats received the extract for 7 days via the drinking water. The reason for this discrepancy between the two investigations remains unclear but since in both studies the exact amount of mg extract per $\mathrm{kg} /$ body weight is not clearly presented and both studies used distinct routes of administration, it is possible that differences in the outcome are related to dose and/or administration variations. Studies in rats revealed that pretreatment with a Phyllantus niruri extract significantly reduced calculous growth after ingesting the tea for three months [51]. When P. niruri treatment was initiated on the first day after implantation of a $\mathrm{CaOx}$ seed into the bladder of rats, a significant inhibition in the growth of the calculi was observed indicating a preventive effect of the plant extract. In contrast, treatment with the extract in the presence of a preformed calculus did not prevent further calculus stone growth; it rather promoted the adsorption of glycosaminoglycans into the calculi, making the stones smaller and softer [51]. These results confirmed an earlier study [52] and suggest that $P$. niruri may have a potential inhibitory effect on the development of urinary 


\begin{tabular}{|ll|}
\hline Country & Plant \\
\hline India & Sesbania grandiflora (L.) Pers. [84]; Aerva lanata(L.) Juss. Ex. Schult. [85, 86] \\
\hline & Moringa oleifera Lam. [87]; Asparagus racemosus Willd. [88] \\
& Rotula aquatica Lour. [89]; Cyclea peltata (Lam.) Hook.f.\& Thoms. [90] \\
& Tribulus terrestris L. [91]; Musa sapienta L. (banana stem) [92] \\
& Ammannia baccifera L. [93]; Mimosa pudica L. [94] \\
\hline & Crataeva nurvala Buch-Ham. [95] \\
\hline Japan & Alisma orientale (Sam.) Juz. (Takusha) [42] \\
\hline & Desmodium styracifolium (Osbeck) Merr. [96]; Quercus salicina Blume [97] \\
\hline Brasil & Phyllanthus niruri L. [51]; Costus spiralis (Jacq.) Roscoe [98] \\
\hline China & Wulingsan [= mixture of Alisma orientale (Sam.) Juz., Polyporus umbellatus Pers., Atractylodes macrocephala \\
& Koidz., Poria cocos (Schw.) Wolf, Cinnamomum cassia (L.) Presl.] [99] \\
\hline & Niao shi [= mixture of Desmodium styracifolium (Osbeck) Merr., Abrus cantoniensis Hance, Pyrrosia petiole L., \\
\hline Mexico & Rmilax glabra Roxb.] [100] \\
\hline Morocco & Trigonella foenum graecum L. [103]; Herniaria hirsuta L. [32] \\
\hline Iran & Nigella sativa L. [104] \\
\hline Others & Rubia tinctorum L. [105]; Rosa canina L. [54] \\
\hline & Punica granatum L. (pomegranate juice) [58] \\
\hline & Citrus limon (L.) Burm. f. (lemon juice) [55] \\
\hline
\end{tabular}

Table 2 Ethnobotanical distribution of plants for which data from animal experiments exist. calculi, probably by hindering the deposition of crystalline material on the stone nidus. The data of both in vivo studies indicate that $P$. niruri probably interferes with the biomineralization process by promoting a different interaction between the crystal and the macromolecules of the organic matrix. The data are also in line with results from in vitro studies in which the plant extract reduced $\mathrm{CaOx}$ crystal aggregation and growth rate [33].

As mentioned earlier, alkali citrate increases urinary $\mathrm{pH}$ and citrate, therefore inhibiting calcium oxalate crystallization [28]. The fact that any alkali citrate would be adequate to increase urinary $\mathrm{pH}$ and citrate provides an interesting approach for further research. Since certain fruit juices have high concentrations of citrate (38.3-67.4 mmol/L) [53], intake of these juices could also be considered for the management of stone disease. It was shown by Grases et al. [54] that an infusion of Rosa canina L. increased citrate excretion without changing volume, $\mathrm{pH}$, or urinary concentrations of oxalate or phosphate. Touhami et al. [55] reported that rats treated with ethylene glycol-ammonium chloride (EG-AC) had large deposits of calcium oxalate crystals in all parts of the kidney, and that such deposits were not present in rats treated with either $75 \%$ or $100 \%$ lemon juice [Citrus limon (L.) Burm. f.] Furthermore, calcific parenchymatous deposits were not observed in $83 \%$ of rats treated with $75 \%$ or $100 \%$ lemon juice. All rats treated with $50 \%$ lemon juice showed fewer calcium deposits on the kidney surface than the group that received EG-AC alone, but treatment with $75 \%$ and $100 \%$ of the juice seemed to be more beneficial [55]. Unfortunately, urinary citrate and $\mathrm{pH}$ were not determined in this study. However, in order to decrease urinary $\mathrm{pH}$ in rats it is necessary to administer an EG dose of $2 \%$ to induce metabolic acidosis - but in the study of Touhami et al. [55] EG was administered in a concentration of $0.75 \%$ which has been shown not to change the urinary $\mathrm{pH}$ value [44]. Consequently, it is unlikely that the administration of citrate will therefore cause changes in urinary citrate excretion. However, this remains speculative since besides the lack of measuring urinary $\mathrm{pH}$ and citrate excretion the amount of citrate and other potential active ingredients in the juice were also not determined in this study. This would have been of interest since it has been shown that lemon juice has a high antioxidant capacity due to its amount of citrate and flavonoids [56,57]. Antioxidants such as flavonoids or other polyphenols could prevent $\mathrm{CaOx}$ crystal deposition in the kidney by preventing hyperoxaluria-induced oxidative damage to the renal tubular membrane which can prevent $\mathrm{CaOx}$ crystal attachment and subsequent development of kidney stones [55].

Against this background, Tugcu et al. [58] administered pomegranate juice (Punica granatum L.) to stone-forming rats to investigate its possible effects on urolithiasis and its mechanism of action. The authors could show that treatment with pomegranate juice decreased urinary Ox excretion and $\mathrm{CaOx}$ deposit formation if compared with rats receiving EG only. In addition, concentrations of malondialdehyde (MDA) and nitric oxide (NO) were significantly lower and glutathione levels (GSH) were higher in the kidneys of rats receiving pomegranate juice. The experiment showed that pomegranate had protective effects on EG induced crystal deposition in rats probably due to its antioxidative activity. Unfortunately, the juice was not further phytochemically characterized so that the amount of ingested antioxidants remains unclear.

In summary, although the majority of in vivo studies in rats has proven that certain plant extracts or fruit juices decrease the excretion of urinary calcium and oxalate and show a potential inhibitory effect on the development of urinary calculi, the precise mechanism of action is still unclear. The prospective therapeutic implication is also restricted by the fact that the used plant extracts have not been further phytochemically characterized which to some degree limits the informative value of the data because statements regarding active compounds remain speculative at present.

\section{Clinical trials}

From the 21 clinical studies that were identified using the inclusion criteria for this review the majority of articles $(n=9)$ evaluated the impact of citrus juices (orange juice, lemon juice, grapefruit juice, apple juice or lemonade) on kidney stone formation. Other studies that met the inclusion criteria focused on the effect of cranberry juice $(\mathrm{n}=3)$, Hibiscus sabdariffa $\mathrm{L}$. $(\mathrm{n}=2)$, Phyllantus niruri $\mathrm{L}$. $(\mathrm{n}=2)$, Orthosiphon grandiflorus Bold. (new: Orthosiphon stamineus Benth. or syn. Clerodendranthus spicatus Thunb.) ( $\mathrm{n}=1)$, Dolichos biflores L. [Vigna unguiculata (L.) Walp. subsp. Unguiculata] $(\mathrm{n}=1)$, Andrographis paniculata L. $(\mathrm{n}=1)$, Sambucus nigra $\mathrm{L}$. $(\mathrm{n}=1)$, and Solidago virgaurea $\mathrm{L} .(\mathrm{n}=1)$. 
As pointed out previously, citrate is a known inhibitor of calciumbased stones. Its presence in urine decreases the saturation of calcium oxalate and calcium phosphate by forming soluble complexes with calcium. By its conversion through bicarbonate citrate increases urinary $\mathrm{pH}$ which induces an additional citraturic response by slowing renal citrate metabolism and impairing citrate reabsorption [28]. However, pharmacological potassium citrate supplementation requires a rigorous schedule of numerous tablets or liquid supplements taken routinely 3 to 4 times a day. Patient compliance significantly decreases when medications are administered more than once daily [59]. Patients therefore could benefit from intake of dietary citrate. Citrus fruits and juices are a known natural source of dietary citrate. Several studies investigated the influence of orange and grapefruit juice on urinary variables and the risk of crystallization $[60,61]$. As observed by Wabner and Pak [60], consumption of $1.2 \mathrm{~L}$ of orange juice (Citrus aurantium var. sinensis $\mathrm{L}$.) per day caused increases in urine $\mathrm{pH}$ and citrate similar to a conventional dose of potassium citrate. In another investigation the impact of orange, grapefruit [Citrus $X$ paradisi Macfad. (pro sp.)] or apple juice [Malus pumila P. Mill; syn: Malus domestica Borkh. (Borkh.)] on urinary composition and crystallization was examined [62]. The authors noticed an increased $\mathrm{pH}$ value and increased citrate excretion after consumption of each juice; CaOx crystallization was significantly reduced by grapefruit and apple juice but not by orange juice. Two additional studies investigated the effect of grapefruit juice on urinary excretion of citrate and other urinary risk factors for renal stone formation. Goldfarb and Asplin [63] found that administration of grapefruit juice over a 7-day period to healthy subjects increased mean oxalate and citrate excretion when compared to the control group. However, no net change in the supersaturation of calcium oxalate, calcium phosphate, or uric acid was observed in this study. Trinchieri et al. [64] evaluated changes in urinary risk factors after administration of a soft drink containing grapefruit juice. In this study, urinary flow was significantly increased after both grapefruit juice and mineral water compared to baseline. Compared to mineral water, grapefruit juice significantly increased urinary excretion of citrate, calcium and magnesium.

In comparison to orange and grapefruit juice, lemon juice [Citrus limon (L.) Burm. f.] contains the highest concentration of citrate, nearly 5 times that of oranges [65]. So far 4 studies have investigated lemonade therapy as a potential treatment for hypocitraturic nephrolithiasis $[65,66]$. The studies concluded that consumption of lemonade significantly increased urinary citrate excretion and therefore could be a useful adjunctive therapy in patients with hypocitraturia. Four ounces of lemon juice provide $5.9 \mathrm{~g}$ citric acid [65]. When diluted in $32 \mathrm{oz}(960 \mathrm{~mL}$ ) of water, lemonade could not only promote dietary citrate but also fluids [67].

All of the mentioned studies have shown that citrus fruit juices consumption delivers a high citric acid load resulting in elevated urinary citrate levels. Since these juices are also well tolerated and inexpensive they could be considered as an alternative or at least an adjunctive therapy for hypocitraturic stone formers. The limitation of most studies, however, is that they have been carried out in either healthy subjects (small sample size studies) or with a larger sample size in patients but therefore being retrospective. Thus, further research is needed in stone-forming patients. In addition, the phytochemical composition of the administered juices remains unclear. Furthermore, the influence of single compounds from citrus juices has not been examined until now.
Cranberry (Vaccinium macrocarpon Ait.) juice is another juice that has been investigated in clinical trials for its ability to influence urinary biochemical and physicochemical risk factors associated with $\mathrm{CaOx}$ kidney stones. However, the literature regarding the effects of cranberry juice on urinary stone risk factors has yielded conflicting results. Urinary calcium has been found to be increased [68], or unchanged [69,70]. Similarly, oxalate has been reported to be either increased $[68,70]$ or decreased [69] and $\mathrm{pH}$ values have been shown to be decreased $[68,70]$ or increased [69]. The reasons for these conflicting results might be due to the variability in the amount ( $330 \mathrm{~mL}-1 \mathrm{~L}$ per day) of cranberry juice ingested, the source and/or the duration of intake ( 5 days to 2 weeks). Further, the study population was relatively small (12-24 subjects) and in all trials healthy subjects have been used. In order to clarify the potential role of cranberry juice on urinary stone risk factors, juices should be evaluated in the future in prospective, double-blind, randomized studies in larger numbers to reach a final conclusion. Since compounds in cranberry juice have been shown to inhibit the attachment of bacteria to the epithelial lining of the urinary tract [71], the same compounds could inhibit the attachment of CaOx crystals and stonepromoting bacteria to renal epithelial cells. Thus, plant extracts that exert antibacterial activities could also have antilithogenic properties by protecting epithelial cells. In fact, Muangman et al. [72] could demonstrate that Andrographis paniculata tablets were beneficial in the treatment of post-ESWL urinary tract infection. In this study post-ESWL pyuria and hematuria in patients receiving Andrographis paniculata were significantly reduced when compared to pre-ESWL values. Other plants which should be mentioned in this context are Arctostaphylos uva-ursi L. or Equisetum arvense L. since they also have known antiseptic activities [73].

As reported formerly, for the prevention of stone formation a high fluid intake is important because a reduced urinary volume will amplify the saturation of all solutes. Recommended fluids include mineral water and fruit juices. Plant extracts which increase urinary volume could therefore also be used as an adjunctive therapy. There are a growing number of studies purporting diuretic effects with traditional medicines. Of these, the most promising are Solidago virgaurea L. [74], Sambucus nigra L. [75] and Hibiscus sabdariffa L. [76,77]. Prasongwatana et al. [77] also report an increased uric acid excretion and clearance after consumption of $H$. sabdariffa tea in study subjects with or without a history of renal stones. On the contrary, Kirdpon et al. [76] found a decrease in uric acid after consumption of a juice prepared from H. sabdariffa. An increase of uric acid excretion was also noted after consumption of a tea prepared from Orthosiphon grandiflorus (new: Orthosiphon stamineus Benth. or syn. Clerodendranthus spicatus Thunb.) [78]. The authors also noticed a stone size reduction in patients which was probably related to an increased excretion of calcium and uric acid. Recently, the authors Yuliana et al. [79] could show in in vitro experiments that the antilithogenic activity of 0 . grandiflorus might be due to its diuretic activity. The authors demonstrated that methoxyflavonoids from Orthosiphon act as antagonists at adenosine $A_{1}$ receptors. Some studies revealed that adenosine $A_{1}$ receptor antagonists can induce diuresis and sodium excretion [80]. Since adenosine $A_{1}$ receptors are expressed in the afferent arterioles, glomerulus, proximale tubules, and collecting ducts adenosine antagonists could directly inhibit sodium reabsorption in the proximal tubules or indirectly by promoting afferent arteriole dilatation [81]. 
However, since only a very limited number of clinical studies have been performed with these two plants the overall benefits are not very clear yet and it is recommended that further studies are conducted to clarify the reported effects.

As mentioned in the previous paragraph, it has been shown that Phyllantus niruri has an inhibitory effect on CaOx crystal growth and aggregation in vitro [33] and prevented the increase in the size and number of formed crystals in a rat model [51,52]. These results could be confirmed in a clinical trial [82]. The study revealed that if patients took capsules containing a $2 \%$ aqueous extract of $P$. niruri ( $450 \mathrm{mg}$ capsule, $3 \times \mathrm{d}$ ) for 3 months urinary calcium was significantly reduced in hypercalciuric patients. Furthermore, regular self-administration ( $2 \mathrm{~g}$ per day for 3 months) of a $P$. nuriri extract after ESWL for renal stones resulted in an increased stone-free rate [83]. The authors concluded that the lack of side effects supports the use of $P$. niruri to improve overall outcomes after ESWL for lower pole stones. It is worth mentioning in this context that from all studies that were included in the present review a phytochemical profile only exists for $P$. niruri [82].

\section{Conclusion}

The effects of various plants with proposed application to prevent and treat stone kidney formation have been critically reviewed in the present article. Data from in vitro, in vivo and clinical trials reveal that phytotherapeutic agents could be useful as either an alternative or a complementary therapy in the management of urolithiasis. The reviewed studies show that some possible mechanisms of action of plant extracts include an increased excretion of urinary citrate, decreased excretion of urinary calcium and oxalate or could be attributable to diuretic, antioxidant or antibacterial effects. Beyond the promising data on activity and efficacy, data on quality of extracts have to be taken into consideration as well. Unfortunately, the documented phytochemical characterization of all herbal preparations in the reviewed articles is inadequate. Future scientific and clinical studies about the efficacy of herbal extracts would highly benefit from an adequate phytochemical description of the extract. Even though most of the reports fail to rigorously define the specific herbal product used in in vitro, in vivo or clinical studies, investigators are increasingly aware that significant differences in the outcome are likely to be product-specific. It is further suggested that products used for research/clinical studies should be characterized by the extraction solvent, drug-extract ratio and the amount of specific marker compounds. This information should allow a more substantial discussion of the data and would help to better explain discrepancies between the studies. Additionally, more studies are needed which focus on the mechanism of action of the extract and active ingredients. The need of the hour is to develop an effective, safe and standardized herbal preparation for the management of urolithiasis. Systematic research needs to be undertaken, in an attempt to explore botanicals as alternative and/or complementary medicines for the treatment of urolithiasis. In conclusion, more interdisciplinary research between pharmacognosists, pharmacologist and clinical investigators is needed to develop new plant-derived high-quality natural products to treat and prevent the formation of kidney stones.

\section{References}

1 Moe OW. Kidney stones: pathophysiology and medical management. Lancet 2006; 367: 333-344

2 Tiselius HG. Epidemiology and medical management of stone disease. BJU Int 2003; 91: 758-767

3 Devuyst 0 , Pirson $Y$. Genetics of hypercalciuric stone forming diseases. Kidney Int 2007; 72: 1065-1072

4 Knoll T. Stone disease. Eur Urol Suppl 2007; 6: 717-722

5 Worcester EM, Coe FL. Nephrolithiasis. Prim Care 2008; 35: 369-391

6 Taylor EN, Stampfer MJ, Curhan GC. Obesity, weight gain, and the risk of kidney stones. JAMA 2005; 293: 455-462

7 Obligado SH, Goldfarb DS. The association of nephrolithiasis with hypertension and obesity: a review. Am J Hypertens 2008; 21: 257-264

8 Coll DM, Varanelli MJ, Smith RC. Relationship of spontaneous passage of ureteral calculi to stone size and location as revealed by unenhanced helical CT. AJR Am J Roentgenol 2002; 178: 101-103

9 Nabi G, Downey P, Keeley F, Watson G, McClinton S. Extra-corporeal shock wave lithotripsy (ESWL) versus ureteroscopic management for ureteric calculi. Cochrane Database Syst Rev 2007: CD006029

10 Tombolini P, Ruoppolo M, Bellorofonte C, Zaatar C, Follini M. Lithotripsy in the treatment of urinary lithiasis. J Nephrol 2000; 13 (Suppl.3): S71-S82

11 Dellabella M, Milanese G, Muzzonigro G. Medical-expulsive therapy for distal ureterolithiasis: randomized prospective study on role of corticosteroids used in combination with tamsulosin-simplified treatment regimen and health-related quality of life. Urology 2005; 66: 712-715

12 Asplin J, Parks J, Lingeman J, Kahnoski R, Mardis H, Lacey S, Goldfarb D, Grasso M, Coe F. Supersaturation and stone composition in a network of dispersed treatment sites. J Urol 1998; 159: 1821-1825

13 Daudon M, Lacour B, Jungers $P$. High prevalence of uric acid calculi in diabetic stone formers. Nephrol Dial Transplant 2005; 20: 468-469

14 Park S, Pearle MS. Pathophysiology and management of calcium stones. Urol Clin North Am 2007; 34: 323-334

15 Miller NL, Evan AP, Lingeman JE. Pathogenesis of renal calculi. Urol Clin North Am 2007; 34: 295-313

16 Khan SR. Renal tubular damage/dysfunction: key to the formation of kidney stones. Urol Res 2006; 34: 86-91

17 Khan SR, Kok DJ. Modulators of urinary stone formation. Front Biosci 2004; 9: 1450-1482

18 Fasano JM, Khan SR. Intratubular crystallization of calcium oxalate in the presence of membrane vesicles: an in vitro study. Kidney Int 2001; 59: 169-178

19 Khan SR, Glenton PA, Backov R, Talham DR. Presence of lipids in urine, crystals and stones: implications for the formation of kidney stones. Kidney Int 2002; 62: 2062-2072

20 Silberstein J, Lakin CM, Kellogg Parsons J. Shock wave lithotripsy and renal hemorrhage. Rev Urol 2008; 10: 236-241

21 Hassan I, Zietlow SP. Acute pancreatitis after extracorporeal shock wave lithotripsy for a renal calculus. Urology 2002; 60: 1111

22 Rashid P, Steele D, Hunt J. Splenic rupture after extracorporeal shock wave lithotripsy. J Urol 1996; 156: 1756-1757

23 Rubin JI, Arger PH, Pollack HM, Banner MP, Coleman BG, Mintz MC, Van Arsdalen KN. Kidney changes after extracorporeal shock wave lithotripsy: CT evaluation. Radiology 1987; 162: 21-24

24 Krambeck $A E$, Gettman MT, Rohlinger AL, Lohse CM, Patterson DE, Segura $J W$. Diabetes mellitus and hypertension associated with shock wave lithotripsy of renal and proximal ureteral stones at 19 years of followup. J Urol 2006; 175: 1742-1747

25 Pearle MS, Nadler R, Bercowsky E, Chen C, Dunn M, Figenshau RS, Hoenig DM, McDougall EM, Mutz J, Nakada SY, Shalhav AL, Sundaram C, Wolf Jr $J S$, Clayman RV. Prospective randomized trial comparing shock wave lithotripsy and ureteroscopy for management of distal ureteral calculi. J Urol 2001; 166: 1255-1260

26 Fellstrom B, Danielson BG, Karlstrom B, Lithell H, Ljunghall S, Vessby B, Wide $L$. Effects of high intake of dietary animal protein on mineral metabolism and urinary supersaturation of calcium oxalate in renal stone formers. Br J Urol 1984; 56: 263-269

27 Laerum E, Larsen S. Thiazide prophylaxis of urolithiasis. A double-blind study in general practice. Acta Med Scand 1984; 215: 383-389

28 Mattle D, Hess B. Preventive treatment of nephrolithiasis with alkali citrate - a critical review. Urol Res 2005; 33: 73-79

29 Achilles $W$. In vitro crystallisation systems for the study of urinary stone formation. World J Urol 1997; 15: 244-251

30 Verkoelen CF, van der Boom BG, Schroder FH, Romijn JC. Cell cultures and nephrolithiasis. World J Urol 1997; 15: 229-235 
31 Atmani F, Khan SR. Effects of an extract from Herniaria hirsuta on calcium oxalate crystallization in vitro. BJU Int 2000; 85: 621-625

32 Atmani F, Farell G, Lieske JC. Extract from Herniaria hirsuta coats calcium oxalate monohydrate crystals and blocks their adhesion to renal epithelial cells. J Urol 2004; 172: 1510-1514

33 Barros ME, Schor N, Boim MA. Effects of an aqueous extract from Phyllantus niruri on calcium oxalate crystallization in vitro. Urol Res 2003; 30: 374-379

34 Campos AH, Schor N. Phyllanthus niruri inhibits calcium oxalate endocytosis by renal tubular cells: its role in urolithiasis. Nephron 1999; 81: 393-397

35 Garimella TS, Jolly CI, Narayanan S. In vitro studies on antilithiatic activity of seeds of Dolichos biflorus Linn. and rhizomes of Bergenia ligulata Wall. Phytother Res 2001; 15: 351-355

36 Chen YC, Ho CY, Chen LD, Hsu SF, Chen WC. Wu-Ling-San formula inhibits the crystallization of calcium oxalate in vitro. Am J Chin Med 2007; 35: 533-541

37 Koide T, Yamaguchi S, Utsunomiya M, Yoshioka T, Sugiyama K. The inhibitory effect of kampou extracts on in vitro calcium oxalate crystallization and in vivo stone formation in an animal model. Int J Urol 1995; 2: 81-86

38 Oussama A, Touhami M, Mbarki M. In vitro and in vivo study of effect of lemon juice on urinary lithogenesis. Arch Esp Urol 2005; 58: 10871092

39 Kulaksizoglu S, Sofikerim M, Cevik C. In vitro effect of lemon and orange juices on calcium oxalate crystallization. Int Urol Nephrol 2008; 40: 589-594

40 Hackett RL, Shevock PN, Khan SR. Cell injury associated calcium oxalate crystalluria. J Urol 1990; 144: 1535-1538

41 Khan SR, Shevock PN, Hackett RL. Membrane-associated crystallization of calcium oxalate in vitro. Calcif Tissue Int 1990; 46: 116-120

42 Moriyama MT, Miyazawa K, Noda K, Oka M, Tanaka M, Suzuki K. Reduction in oxalate-induced renal tubular epithelial cell injury by an extract from Quercus salicina Blume/Quercus stenophylla Makino. Urol Res 2007: 35: 295-300

43 Jeong BC, Kim BS, Kim JI, Kim HH. Effects of green tea on urinary stone formation: an in vivo and in vitro study. J Endourol 2006; 20: 356-361

44 Khan SR. Animal models of kidney stone formation: an analysis. World J Urol 1997; 15: 236-243

45 Yasui T, Fujita K, Sato M, Sugimoto M, Iguchi M, Nomura S, Kohri K. The effect of takusha, a kampo medicine, on renal stone formation and osteopontin expression in a rat urolithiasis model. Urol Res 1999; 27 : 194-199

46 Buffington CA, Blaisdell JL, Komatsu Y, Kawase K. Effects of choreito and takushya consumption on in vitro and in vivo struvite solubility in cat urine. Am J Vet Res 1997; 58: 150-152

47 Buffington CA, Blaisdell JL, Kawase K, Komatsu Y. Effects of choreito consumption on urine variables of healthy cats fed a magnesium-supplemented commercial diet. Am J Vet Res 1997; 58: 146-149

48 Atmani F, Slimani Y, Mimouni M, Aziz M, Hacht B, Ziyyat A. Effect of aqueous extract from Herniaria hirsuta L. on experimentally nephrolithiasic rats. J Ethnopharmacol 2004; 95: 87-93

49 Atmani F, Slimani Y, Mimouni M, Hacht B. Prophylaxis of calcium oxalate stones by Herniaria hirsuta on experimentally induced nephrolithiasis in rats. BJU Int 2003; 92: 137-140

50 Grases F, Ramis M, Costa-Bauza A, March JG. Effect of Herniaria hirsuta and Agropyron repens on calcium oxalate urolithiasis risk in rats. J Ethnopharmacol 1995; 45: 211-214

51 Barros ME, Lima R, Mercuri LP, Matos JR, Schor N, Boim MA. Effect of extract of Phyllanthus niruri on crystal deposition in experimental urolithiasis. Urol Res 2006; 34: 351-357

52 Freitas AM, Schor N, Boim MA. The effect of Phyllanthus niruri on urinary inhibitors of calcium oxalate crystallization and other factors associated with renal stone formation. BJU Int 2002; 89: 829-834

53 Haleblian GE, Leitao VA, Pierre SA, Robinson MR, Albala DM, Ribeiro AA, Preminger GM. Assessment of citrate concentrations in citrus fruitbased juices and beverages: implications for management of hypocitraturic nephrolithiasis. J Endourol 2008; 22: 1359-1366

54 Grases F, Masarova L, Costa-Bauza A, March JG, Prieto R, Tur JA. Effect of "Rosa Canina" infusion and magnesium on the urinary risk factors of calcium oxalate urolithiasis. Planta Med 1992; 58: 509-512

55 Touhami M, Laroubi A, Elhabazi K, Loubna F, Zrara I, Eljahiri Y, Oussama $A$, Grases $F$, Chait $A$. Lemon juice has protective activity in a rat urolithiasis model. BMC Urol 2007; 7: 18
56 Minato K, Miyake Y, Fukumoto S, Yamamoto K, Kato Y, Shimomura Y, Osawa T. Lemon flavonoid, eriocitrin, suppresses exercise-induced oxidative damage in rat liver. Life Sci 2003; 72: 1609-1616

57 Yu J, Wang L, Walzem RL, Miller EG, Pike LM, Patil BS. Antioxidant activity of citrus limonoids, flavonoids, and coumarins. J Agric Food Chem 2005; 53: 2009-2014

58 Tugcu V, Kemahli E, Ozbek E, Arinci YV, Uhri M, Erturkuner P, Metin G, Seckin I, Karaca C, Ipekoglu N, Altug T, Cekmen MB, Tasci AI. Protective effect of a potent antioxidant, pomegranate juice, in the kidney of rats with nephrolithiasis induced by ethylene glycol. J Endourol 2008; 22: 2723-2731

59 Cramer JA, Mattson RH, Prevey ML, Scheyer RD, Ouellette VL. How often is medication taken as prescribed? A novel assessment technique. JAMA 1989; 261: 3273-3277

60 Wabner CL, Pak CY. Effect of orange juice consumption on urinary stone risk factors. J Urol 1993; 149: 1405-1408

61 Odvina CV. Comparative value of orange juice versus lemonade in reducing stone-forming risk. Clin J Am Soc Nephrol 2006; 1: 1269-1274

62 Honow R, Laube N, Schneider A, Kessler T, Hesse A. Influence of grapefruit-, orange- and apple-juice consumption on urinary variables and risk of crystallization. Br J Nutr 2003; 90: 295-300

63 Goldfarb DS, Asplin JR. Effect of grapefruit juice on urinary lithogenicity. J Urol 2001; 166: 263-267

64 Trinchieri A, Lizzano $R$, Bernardini P, Nicola M, Pozzoni F, Romano AL, Serrago MP, Confalanieri S. Effect of acute load of grapefruit juice on urinary excretion of citrate and urinary risk factors for renal stone formation. Dig Liver Dis 2002; 34 (Suppl. 2): S160-S163

65 Seltzer MA, Low RK, McDonald M, Shami GS, Stoller ML. Dietary manipulation with lemonade to treat hypocitraturic calcium nephrolithiasis. J Urol 1996; 156: 907-909

66 Kang DE, Sur RL, Haleblian GE, Fitzsimons NJ, Borawski KM, Preminger GM. Long-term lemonade based dietary manipulation in patients with hypocitraturic nephrolithiasis. J Urol 2007; 177: 1358-1362; discussion 62

67 Penniston KL, Steele TH, Nakada SY. Lemonade therapy increases urinary citrate and urine volumes in patients with recurrent calcium oxalate stone formation. Urology 2007; 70: 856-860

68 Gettman MT, Ogan K, Brinkley LJ, Adams-Huet B, Pak CY, Pearle MS. Effect of cranberry juice consumption on urinary stone risk factors. J Urol 2005; 174: 590-594

69 McHarg T, Rodgers A, Charlton K. Influence of cranberry juice on the urinary risk factors for calcium oxalate kidney stone formation. BJU Int 2003; 92: 765-768

70 Kessler T, Jansen B, Hesse A. Effect of blackcurrant-, cranberry- and plum juice consumption on risk factors associated with kidney stone formation. Eur J Clin Nutr 2002; 56: 1020-1023

71 Howell AB, Vorsa N, Der Marderosian A, Foo LY. Inhibition of the adherence of P-fimbriated Escherichia coli to uroepithelial-cell surfaces by proanthocyanidin extracts from cranberries. N Engl J Med 1998; 339: 1085-1086

72 Muangman V, Viseshsindh V, Ratana-Olarn K, Buadilok S. The usage of Andrographis paniculata following extracorporeal shock wave lithotripsy (ESWL). J Med Assoc Thai 1995; 78: 310-313

73 Grases F, Melero G, Costa-Bauza A, Prieto R, March JG. Urolithiasis and phytotherapy. Int Urol Nephrol 1994; 26: 507-511

74 Melzig MF. Goldenrod - a classical exponent in the urological phytotherapy. Wien Med Wochenschr 2004; 154: 523-527

75 Walz B, Chrubasik S. Impact of a proprietary concentrate of Sambucus nigra L. on urinary pH. Phytother Res 2008; 22: 977-978

76 Kirdpon S, Nakorn SN, Kirdpon W. Changes in urinary chemical composition in healthy volunteers after consuming roselle (Hibiscus sabdariffa Linn.) juice. J Med Assoc Thai 1994; 77: 314-321

77 Prasongwatana V, Woottisin S, Sriboonlue P, Kukongviriyapan V. Uricosuric effect of Roselle (Hibiscus sabdariffa) in normal and renal-stone former subjects. J Ethnopharmacol 2008; 117: 491-495

78 Premgamone A, Sriboonlue P, Disatapornjaroen W, Maskasem S, Sinsupan $N$, Apinives $C$. A long-term study on the efficacy of a herbal plant, Orthosiphon grandiflorus, and sodium potassium citrate in renal calculi treatment. Southeast Asian J Trop Med Public Health 2001; 32: 654660

79 Yuliana ND, Khatib A, Link-Struensee AM, Ijzerman AP, Rungkat-Zakaria $F$, Choi $Y H$, Verpoorte $R$. Adenosine A1 receptor binding activity of methoxy flavonoids from Orthosiphon stamineus. Planta Med 2009; 75: 132-136 
80 Modlinger PS, Welch WJ. Adenosine A1 receptor antagonists and the kidney. Curr Opin Nephrol Hypertens 2003; 12: 497-502

81 Poulsen SA, Quinn RJ. Adenosine receptors: new opportunities for future drugs. Bioorg Med Chem 1998; 6: 619-641

82 Nishiura JL, Campos AH, Boim MA, Heilberg IP, Schor N. Phyllanthus niruri normalizes elevated urinary calcium levels in calcium stone forming (CSF) patients. Urol Res 2004; 32: 362-366

83 Micali S, Sighinolfi MC, Celia A, De Stefani S, Grande M, Cicero AF, Bianchi G. Can Phyllanthus niruri affect the efficacy of extracorporeal shock wave lithotripsy for renal stones? A randomized, prospective, longterm study. J Urol 2006; 176: 1020-1022

84 Doddola S, Pasupulati H, Koganti B, Prasad KV. Evaluation of Sesbania grandiflora for antiurolithiatic and antioxidant properties. Nat Med (Tokyo) 2008; 62: 300-307

85 Soundararajan P, Mahesh R, Ramesh T, Begum VH. Effect of Aerva lanata on calcium oxalate urolithiasis in rats. Indian J Exp Biol 2006; 44: 981 986

86 Selvam R, Kalaiselvi P, Govindaraj A, Bala Murugan V, Sathish Kumar AS. Effect of $A$. lanata leaf extract and Vediuppu chunnam on the urinary risk factors of calcium oxalate urolithiasis during experimental hyperoxaluria. Pharmacol Res 2001; 43: 89-93

87 Karadi RV, Gadge NB, Alagawadi KR, Savadi RV. Effect of Moringa oleifera Lam. root-wood on ethylene glycol induced urolithiasis in rats. J Ethnopharmacol 2006; 105: 306-311

88 Christina AJ, Ashok K, Packialakshmi M, Tobin GC, Preethi J, Murugesh N. Antilithiatic effect of Asparagus racemosus Willd on ethylene glycol-induced lithiasis in male albino Wistar rats. Methods Find Exp Clin Pharmacol 2005; 27: 633-638

89 Christina AJ, Priya Mole M, Moorthy P. Studies on the antilithic effect of Rotula aquatica lour in male Wistar rats. Methods Find Exp Clin Pharmacol 2002; 24: 357-359

90 Christina AJ, Packia Lakshmi M, Nagarajan M, Kurian S. Modulatory effect of Cyclea peltata Lam. on stone formation induced by ethylene glycol treatment in rats. Methods Find Exp Clin Pharmacol 2002; 24: 7779

91 Anand R, Patnaik GK, Kulshreshtha DK, Dhawan BN. Activity of certain fractions of Tribulus terrestris fruits against experimentally induced urolithiasis in rats. Indian J Exp Biol 1994; 32: 548-552

92 Poonguzhali PK, Chegu H. The influence of banana stem extract on urinary risk factors for stones in normal and hyperoxaluric rats. Br J Urol 1994; $74: 23-25$
93 Prasad KV, Bharathi K, Srinivasan KK. Evaluation of Ammannia baccifera Linn. for antiurolithic activity in albino rats. Indian J Exp Biol 1994; 32: 311-313

94 Joyamma V, Rao SG, Hrishikeshavan HJ, Aroor AR, Kulkarni DR. Biochemical mechanisms and effects of Mimosa pudica (Linn) on experimental urolithiasis in rats. Indian J Exp Biol 1990; 28: 237-240

95 Varalakshmi P, Shamila Y, Latha E. Effect of Crataeva nurvala in experimental urolithiasis. J Ethnopharmacol 1990; 28: 313-321

96 Hirayama H, Wang Z, Nishi K, Ogawa A, Ishimatu T, Ueda S, Kubo T, Nohara T. Effect of Desmodium styracifolium-triterpenoid on calcium oxalate renal stones. Br J Urol 1993; 71: 143-147

97 Ogawa Y, Takahashi S, Kitagawa R. Effect of herb medicines for urolithiasis on urinary oxalate excretion in rats. Hinyokika Kiyo 1983; 29: $1269-1271$

98 Araujo Viel T, Diogo Domingos C, da Silva Monteiro AP, Riggio LimaLandman MT, Lapa AJ, Souccar C. Evaluation of the antiurolithiatic activity of the extract of Costus spiralis Roscoe in rats. J Ethnopharmacol 1999; 66: 193-198

99 Tsai CH, Chen YC, Chen LD, Pan TC, Ho CY, Lai MT, Tsai FJ, Chen WC. A traditional Chinese herbal antilithic formula, Wulingsan, effectively prevents the renal deposition of calcium oxalate crystal in ethylene glycol-fed rats. Urol Res 2008; 36: 17-24

100 Xue JZ. A preliminary laboratory investigation of "niao shi mixture" in preventing experimental calcium oxalate renal calculus in rats. J Tradit Chin Med 1982; 2: 187-194

101 Vargas Solis R, Perez Gutierrez RM. Diuretic and urolithiatic activities of the aqueous extract of the fruit of Randia echinocarpa on rats. J Ethnopharmacol 2002; 83: 145-147

102 Vargas R, Perez RM, Perez S, Zavala MA, Perez C. Antiurolithiatic activity of Raphanus sativus aqueous extract on rats. J Ethnopharmacol 1999; 68: 335-338

103 Laroubi A, Touhami M, Farouk L, Zrara I, Aboufatima R, Benharref A, Chait A. Prophylaxis effect of Trigonella foenum graecum $\mathrm{L}$. seeds on renal stone formation in rats. Phytother Res 2007; 21: 921-925

104 Hadjzadeh MA, Khoei A, Hadjzadeh Z, Parizady M. Ethanolic extract of Nigella sativa L. seeds on ethylene glycol-induced kidney calculi in rats. Urol J 2007; 4: 86-90

105 Schneider HJ, Unger G, Rossler D, Bothor C, Berg W, Ernst G. Effect of drugs used for the prevention of urinary calculi recurrence on the growth and metabolism of young experimental animals. Z Urol Nephrol 1979; 72: 237-247 